\title{
Association between intratumoral free and total VEGF, soluble VEGFR-I, VEGFR-2 and prognosis in breast cancer
}

\author{
H Bando', HA Weich², M Brokelmann², S Horiguchi', N Funata ${ }^{3}$, T Ogawa' and M Toi, 1,4 \\ 'Department of Surgery, Tokyo Metropolitan Komagome Hospital, Tokyo Metropolitan Cancer and Infectious Disease Center, 3-I 8-22, Honkomagome \\ Bunkyo-ku, Tokyo I I 3-8677, Japan; '2Department of Gene Regulation and Differentiation, National Research Centre for Biotechnology, Braunschweig, \\ Germany; ${ }^{3}$ Department of Pathology, Tokyo Metropolitan Komagome Hospital, Tokyo Metropolitan Cancer and Infectious Disease Center, 3-I 8-22, \\ Honkomagome Bunkyo-ku, Tokyo II 3-8677, Japan; ${ }^{4}$ Department of Clinical Trials and Research, Tokyo Metropolitan Komagome Hospital, Tokyo \\ Metropolitan Cancer and Infectious Disease Center, 3-I 8-22, Honkomagome Bunkyo-ku, Tokyo II 3-8677, Japan
}

Vascular endothelial growth factor (VEGF) receptors consist of three cell-membrane type receptors (VEGFR-I, VEGFR-2 and VEGFR-3), and soluble form of VEGFR-I (sVEGFR-I), an intrinsic negative counterpart of the VEGF. In this study, we measured intratumoral protein levels of free and total VEGF, VEGFR-2 and sVEGFR-I from 202 primary breast cancer tissues and examined their prognostic values. A significant inverse correlation was found between free or total VEGF and oestrogen receptor (ER) status $(P=0.042$ and 0.032 , respectively). A univariate analysis showed that low sVEGFR-I and high total VEGF were significantly associated with poor prognosis in disease-free survival (DFS) and overall survival (OS). The ratio of sVEGFR-I to total VEGF was a strong prognostic indicator (DFS: $P=0.008$; $O S: P=0.0002$ ). A multivariate analysis confirmed the independent prognostic values of total VEGF and the ratio of sVEGFR-I to total VEGF. In subgroup analysis, total VEGF was a significant prognostic indicator for ER-positive tumours but not for ER-negative tumours, whereas SVEGFR-I was significant for ER-negative tumours but not for ER-positive tumours. In conclusion, the intratumoral sVEGFR-I level, VEGF level and the ratio of sVEGFR-I to total VEGF are potent prognostic indicators of primary breast cancer, and might be relevant to ER status.

British Journal of Cancer (2005) 92, 553-56I. doi:I0.1038/sj.bjc.6602374 www.bjcancer.com

Published online 25 January 2005

(c) 2005 Cancer Research UK

Keywords: vascular endothelial growth factor; soluble vascular endothelial growth factor receptor- I; vascular endothelial growth factor receptor-2; neovascularisation; breast cancer

Vascular endothelial growth factor (VEGF) and its receptors are essential for neovascularisation in cancer. Numerous studies have indicated that intratumoral VEGF expression is significantly correlated with microvessel density and poor prognosis in a variety of human solid cancers including breast cancer, brain tumours, head and neck cancer and gastrointestinal cancer (Toi et al, 2001; Ferrara et al, 2003). The prognostic value of VEGF has been confirmed not only in immunohistochemical studies but also in other studies using enzyme-linked immunosorbent assay (ELISA) and Northern blotting. In most clinical studies that examined the prognostic value of VEGF in primary breast cancer, intratumoral VEGF expression was a significant marker of poor prognosis in both node-negative and node-positive subgroups (Gasparini, 2000). Thus, these studies concluded that intratumoral VEGF status is an independent prognostic indicator of primary breast cancer.

VEGF binds to two types of cell-membrane receptors, the VEGF receptor (VEGFR)-1 and VEGFR-2 located in the endothelium, and

\footnotetext{
* Correspondence: Dr M Toi, Metropolitan Komagome Hospital, Tokyo Metropolitan Center for Cancer and Infectious Disease, 3-18-22, Honkomagome Bunkyo-ku, Tokyo I 13-8677, Japan;

E-mail: maktoi77@wa2.so-net.ne.jp

Received 9 August 2004; revised 8 December 2004; accepted 9 December 2004; published online 25 January 2005
}

stimulates endothelial migration, proliferation, permeability and survival (Ferrara and Alitalo 1999; Shibuya, 2001). In addition to these two receptors, a soluble form of VEGFR-1 (sVEGFR-1), a naturally occurring and alternatively spliced variant of sVEGFR-1, functions as a high-affinity receptor of VEGF (Kendall and Thomas, 1993; Kendall et al, 1996). Since sVEGFR-1 is a secretory protein, it is an intrinsic negative counterpart of VEGF signalling. Recombinant sVEGFR1 binds to all isoforms of VEGF and inhibits VEGF-induced endothelial cell proliferation. Gene therapies involving sVEGFR-1 significantly suppress tumour growth in animal experimental models (Goldman et al, 1998; Takayama et al, 2000; Mahasreshti et al, 2001; Hoshida et al, 2002; Sako et al, 2004). Kendall et al (1996) found that sVEGFR1 is abundant in all identified VEGFR-1 cDNAs from human primary endothelial cells. In our preliminary study using primary breast cancer tissues, sVEGFR1 was frequently coexpressed with VEGF, and the intratumoral balance between sVEGFR1 and VEGF levels showed a significant relationship with survival (Toi et al, 2002). According to a recent report on brain tumours, the ratio of sVEGFR-1 to VEGF is significantly decreased in glioblastomas compared with astrocytomas, which indicates the importance of sVEGFR-1 expression in brain tumour growth (Lamszus et al, 2003). It is therefore crucial to investigate the relationship between VEGF and its receptors including sVEGFR-1. Previous studies have indicated that intratumoral sVEGFR-1 levels are frequently elevated in 
human tumour tissues, although the precise upregulation mechanism involving sVEGFR-1 in cancer is largely unknown.

Recently, we have developed a more sensitive sVEGFR-1 ELISA system in addition to new methodologies that permit the separate measurement of free VEGF, which is unbound to the receptors, and total VEGF, which includes both bound and unbound molecules to receptors. In this study, we measured total and free VEGF, sVEGFR-1 and VEGFR-2, as well as Her-2/neu and thymidine phosphorylase (TP) levels in breast tumour cytosols quantitatively and then evaluated those prognostic values. The information from this study is useful not only for assessing the prognostic value of these markers but also for considering the clinical implications of future anti-VEGF therapies paradigm.

\section{MATERIALS AND METHODS}

\section{Patient population}

We randomly selected tissues from 202 patients with operable primary breast cancer who underwent modified radical or partial mastectomy with full dissection of their axillary lymph nodes at the Tokyo Metropolitan Komagome Hospital from 1996 to 1999 with an average follow-up period of 64.0 months and a range of 1.3-93.2 months. Representative samples of the tumour specimens were immediately frozen in liquid nitrogen after surgical resection and stored at $-80^{\circ} \mathrm{C}$ until preparation for ELISA. Pathological examinations were performed on formalin-fixed, paraffin-em-

Table I Patients characteristics

\begin{tabular}{|c|c|}
\hline & Number of patients (\%) \\
\hline Patients enrolled & 202 \\
\hline Median age (years) & 55, range $30-86$ \\
\hline \multicolumn{2}{|l|}{ Menopausal status } \\
\hline Pre & $86(42.6)$ \\
\hline Post & $116(57.4)$ \\
\hline \multicolumn{2}{|l|}{ Tumour size $(\mathrm{cm})$} \\
\hline$<2$ & $26(12.9)$ \\
\hline $2-5$ & $125(61.9)$ \\
\hline$>5$ & $51(25.2)$ \\
\hline \multicolumn{2}{|l|}{ Nodal involvement } \\
\hline - & $94(46.5)$ \\
\hline+ & $108(53.5)$ \\
\hline \multicolumn{2}{|l|}{ ER } \\
\hline Positive & 110 (54.5) \\
\hline Negative & $92(45.5)$ \\
\hline \multicolumn{2}{|l|}{ PgR } \\
\hline Positive & $105(52.0)$ \\
\hline Negative & $97(48.0)$ \\
\hline \multicolumn{2}{|l|}{ Hormonal receptor } \\
\hline ER+ and PR+ & $79(39.1)$ \\
\hline ER+ or PR+ & $56(27.7)$ \\
\hline $\mathrm{ER}-$ and $\mathrm{PR}-$ & $67(33.2)$ \\
\hline \multicolumn{2}{|l|}{ Nuclear grade } \\
\hline 1 1 - n & $39(19.3)$ \\
\hline 2 & $99(49.0)$ \\
\hline 3 & $64(31.7)$ \\
\hline \multicolumn{2}{|l|}{ Recurrence } \\
\hline+ & 57 (28.2) \\
\hline- & 145 (7|.8) \\
\hline \multicolumn{2}{|l|}{ Adjuvant therapy } \\
\hline CAF (CEF) & $54(26.7)$ \\
\hline CMF (CF) & $18(8.9)$ \\
\hline FU derivatives & $38(18.8)$ \\
\hline Tamoxifen & $119(58.9)$ \\
\hline $\mathrm{LH}-\mathrm{RH}$ & $10(5.0)$ \\
\hline
\end{tabular}

$\mathrm{ER}=$ oestrogen receptor; $\mathrm{PgR}=$ progesterone receptor; $\mathrm{CAF} \quad(\mathrm{CEF})=$ cyclophosphamide, adriamycin or epirubicin and 5-FU; CMF (CF)=cyclophosphamide, methotrexate and 5-FU. bedded specimens. The main characteristics of the patients and adjuvant hormone and chemotherapy details are described in Table 1. All patients signed an informed consent according to a protocol approved by the ethics committee of the hospital.

Adjuvant therapy and patient follow-up Indications for and the schedule of adjuvant treatment were decided based on the patient characteristics including axillary nodal involvement (n), tumour size (T), age and oestrogen receptor (ER). Polychemotherapy including six cycles of CA(E)F (cyclophosphamide, adriamycin/ epirubicin and 5-fluorouracil (5-FU)) was given to node-positive patients under the age of 60 years, and FU derivatives were given to the remaining node-positive and high-risk node-negative patients. Tamoxifen was given to hormone receptor-positive patients without a history of thrombosis or liver dysfunction for 5 years and additional LH-RH agonist therapy was undertaken for 2 years for premenopausal cases. The patients received radiation to the remaining breast if partial mastectomy was performed, and to the chest wall and draining lymph nodes if more than four lymph nodes were involved. Post-treatment surveillance was carried out according to general practice for breast cancer patients at our institute. Briefly, for the first 5 years physical examinations, haematology and blood chemistry analyses were performed every 3 months, chest X-rays were taken every 6 months and mammography was performed annually. Thereafter, physical, blood and chest X-ray examinations were performed every 6-12 months, and annual mammography was continued. If tumour relapse was suspected, the patient underwent intensive work-up including chest/abdominal computed tomography scans, isotopic bone scans, bone radiography or histological examination. Survival analysis was performed on 186 cases excluding six patients with ductal carcinoma in situ (DCIS) and 10 patients who did not show up for the follow-up. The outcomes examined included overall survival (OS) and disease-free survival (DFS), which were calculated from the date of surgery. Overall survival was calculated from the date of surgery to last contact for living patients. Diseasefree survival was defined as the period from the date of surgery to the confirmed tumour relapse date for relapsed patients and from the date of surgery to the date of the last follow-up for disease-free patients.

\section{Histopathologic analysis}

Representative sections from all primary tumours were reviewed and analysed by pathologists. The special morphologic features examined included grade, lymph vessel/blood vessel involvement and the number of lymph nodes involved.

Sample preparation Breast tumour tissue samples were treated with two different types of lysis buffer. For the measurement of sVEGFR-1 and TP protein, tissue samples were homogenised in a solution of $10 \mathrm{~mm}$ Tris- $\mathrm{HCl}$ buffer ( $\mathrm{pH} 7.4$ ) containing $15 \mathrm{~mm} \mathrm{NaCl}$, $1.5 \mathrm{mM} \mathrm{MgCl} 2,50 \mu \mathrm{M}$ potassium phosphate and a proteaseinhibitor cocktail. For all other ELISA measurements, samples were individually homogenised in a 10 -fold volume of RIPA buffer $(0.1 \%$ SDS, $1 \%$ Tween $20,0.5 \%$ Na-deoxycholate, proteaseinhibitor cocktail in phosphate-buffered saline, $\mathrm{pH}$ 7.4) and then centrifuged at $14000 \mathrm{~g}$ for $20 \mathrm{~min}$. The supernatants were then stored at $-80^{\circ} \mathrm{C}$ until use. A portion of each supernatant was used for protein concentration measurement according to standard protocols (BCA assay, Pierce, Rockford, IL, USA).

\section{Enzyme-linked immunosorbent assay}

Total VEGF protein concentrations in the tumour cytosols were measured using VEGF ELISA kits (R\&D Systems, Minneapolis, $\mathrm{MN}$, USA). The measurements were conducted according to the 
methods recommended by the manufacturer. The minimal detection limit for total VEGF was $31 \mathrm{pg} \mathrm{ml}^{-1}$.

A receptor-ligand detection assay was applied to detect free bioactive VEGF following the basic protocol for total VEGF ELISA, except that plates were coated with $0.5 \mu \mathrm{g} \mathrm{ml}^{-1}$ sVEGFR-1 (D1D6) produced in insect cells (Hornig et al, 1999). This ensured that no VEGFR-1 complex forms were recognised. For detection, biotinylated anti-VEGF antibody (R\&D Systems, Minneapolis, MN, USA) was used. The minimal detection limit for free VEGF was $20 \mathrm{pg} \mathrm{ml}^{-1}$.

Enzyme-linked immunosorbent assay for sVEGFR-1 was performed as previously reported with modifications to improve sensitivity (Toi et al, 2002). A human sVEGFR-1 ELISA kit (Bender MedSystems, Vienna, Austria) was used according to the manufacturer's protocol. The minimum detection limit was $100 \mathrm{pg} \mathrm{ml}^{-1}$.

The VEGFR-2 protein concentration in tumour lysates was measured using VEGFR-2 ELISA kits (R\&D Systems, Minneapolis, MN, USA). The measurements were conducted according to the methods recommended by the manufacturer. The minimal detection limit for VEGFR-2 was $78 \mathrm{pg} \mathrm{ml}^{-1}$.

Her-2/neu was determined using a Her-2/neu (c-erbB-2) sandwich enzyme immunoassay (Oncogene Science, Cambridge, MA, USA), which employs a mouse monoclonal antibody for capture and a different biotinylated mouse monoclonal antibody for the detection of human neu protein. The capture and detector reagents specifically bind to the extracellular domain of the neu protein. The minimal detection limit for Her-2/neu was $24 \mathrm{pg} \mathrm{ml}^{-1}$.

Thymidine phosphorylase levels were also determined by a colorimetric ELISA. This sandwich immunoassay used two antihuman TP monoclonal antibodies (Nippon Roche Research Center, Kamakura, Japan; 104B and 232-2). The minimal detectable concentration was $1.25 \mathrm{ng} \mathrm{ml}^{-1}$.

Levels of ER and progesterone receptor $(\mathrm{PgR})$ were determined using enzyme immunoassay systems from the Otsuka Assay Institute (Tokushima, Japan) as previously reported. The cutoff value of enzyme immunoassay for ER and PgR was $10 \mathrm{fmol} \mathrm{mg}^{-1}$ protein.

All protein level measurements made by ELISA were performed in duplicate.

\section{Statistical methods}

The correlation between two factors was evaluated using the Spearman's correlation coefficient by rank and unpaired groups were compared using the Student's $t$-test. Univariate and multivariate Cox regression analyses were carried out to assess potential prognostic indicators of DFS and OS. These features included ER and PgR status, tumour grade (low vs intermediate and high grade), tumour size $(5 v s>5 \mathrm{~cm}$ ), axillary lymph node involvement (positive $v s$ negative), lymph vessel involvement (positive $v s$ negative), blood vessel involvement (positive $v s$ negative), total VEGF protein concentration (<mean $v s>$ mean), free VEGF protein concentration ( $<$ mean $v s>$ mean), sVEGFR-1 protein concentration $\left(<0.435\right.$ vs $>0.435 \mathrm{ng} \mathrm{mg}^{-1}$ protein), VEGFR-2 protein concentration (mean $v s>$ mean), Her-2/neu protein concentration $(<$ mean $v s>$ mean), TP protein concentration (mean $v s>$ mean) and sVEGFR-1/total VEGF $(<0.5 v s \geqslant 0.5)$. All clinical and biological parameters regardless of whether they were statistically significant as seen by the univariate analysis were included in the multivariate analysis. Variables that exhibited statistically significant effects were then retained and the others were dropped.

Multivariate analysis resulted in a final model of five prognostic variables for DFS and four prognostic variables for OS. Models were then generated based on the presence or absence of these variables and constructed to assess the relative risk for relapse and death.
Standard Kaplan-Meier and Cox regression methods were applied for survival analysis using the StatView statistical software Version 5.0 (SAS Institute, Cary, NC, USA). All significance testing was two-sided, where log-rank statistics and Wald statistics were used for univariate and multivariate analysis, respectively. Differences for $P<0.05$ were considered to be statistically significant. The last follow-up date was 31st March 2004.

\section{RESULTS}

\section{Patient characteristics}

The patient characteristics are listed in Table 1 . The median age at diagnosis was 55 years with a range of 30-86 years. Five patients who presented with DCIS were excluded from the survival analysis. A total of 110 (54\%) underwent adjuvant chemotherapy, and 64\% of the patients with positive receptor underwent adjuvant hormonal therapy. In all, $66 \%$ of the tumours were ER positive and/or PgR positive, and $81 \%$ were intermediate or high-grade tumours.

The protein concentrations of total VEGF, free VEGF, sVEGFR1, VEGFR-2, TP and Her-2/neu in breast tumour tissue extracts determined by ELISA are listed in Table 2. The correlations between each factor and clinico-pathological parameters were analysed. Total and free VEGF levels were significantly higher in ER-negative tumours, and free VEGF levels were also higher in PgR-negative tumours. Soluble VEGFR-1 levels were higher in PgR-negative tumours, and VEGFR-2 showed no statistically significant correlation with any of the clinico-pathological parameters. Her-2/neu was associated with a larger tumour size, ER negativity and high nuclear grade $(P=0.01,0.04$ and 0.03 , respectively). There was a significant correlation of the protein levels between total VEGF and free VEGF $(P<0.001, \rho=0.905)$, total VEGF and sVEGFR-1 $(P<0.001, \rho=0.278)$, free VEGF and sVEGFR-1 $\quad(P<0.001, \quad \rho=0.251), \quad$ sVEGFR-1 and VEGFR-2 $(P=0.008, \rho=0.190)$, total VEGF and Her-2/neu $(P=0.029$, $\rho=0.157)$, free VEGF and Her-2/neu $(P=0.04, \rho=0.145)$, total VEGF and TP $(P=0.004, \rho=0.207)$, free VEGF and TP $(P=0.017$, $\rho=0.171)$ and sVEGFR- 1 and TP $(P<0.001, \rho=0.270)$, but none was seen between VEGF and VEGFR-2 by Spearman's rank correlation test (data not shown).

To assess the prognostic value of sVEGFR-1 and the ratio of sVEGFR-1 to total VEGF, we determined the cutoff level according to a stepwise method that gives the optimal separation between a low and high risk of relapse as previously described (Toi et al, 2002). The cutoff value for sVEGFR-1 was $0.435 \mathrm{ng} \mathrm{mg}^{-1}$ protein, which identified $15.6 \%$ of the patients enrolled in the survival analysis as having low sVEGFR-1. For total and free VEGF, VEGFR-2, TP and Her-2/neu, the cutoff values were determined as their respective mean values.

According to the combination analysis, the ratio of sVEGFR-1 to total VEGF concentration (S/V ratio) and its prognostic value were assessed using a similar stepwise separation method as described above. Tumours with an associated S/V ratio of 3.0 were considered to be borderline for achieving a prognostic value for survival analysis. A value of 0.5 was decided on as the cutoff value, with $8.6 \%$ of the patients having a low S/V ratio with the most unfavourable prognosis (Table 3 ).

For univariate analyses, patients with low-grade tumours $(P=0.002)$, tumours less than $5 \mathrm{~cm}$ in size $(P=0.0001)$, no lymph node involvement $(P=0.0001)$, less vessel involvement $(P=0.01$ $0.001)$, low total VEGF level $(P=0.002)$, low free VEGF level $(P=0.047)$, high sVEGFR-1 level $(P=0.04)$ and a high $\mathrm{S} / \mathrm{V}$ ratio $(P=0.008)$ experienced favourable DFS (Table 3). Overall survival was favourable for patients with negative $\operatorname{PgR}$ status $(P=0.017)$, low-grade tumours $(P=0.011)$, tumours less than $5 \mathrm{~cm}$ in size $(P=0.0002)$, no lymph node involvement $(P=0.0005)$, less vessel 
Table 2 Quantitation of total and free VEGF, sVEGFR-I, VEGFR-2, Her-2/neu and TP proteins in primary breast cancer tumour cytosol

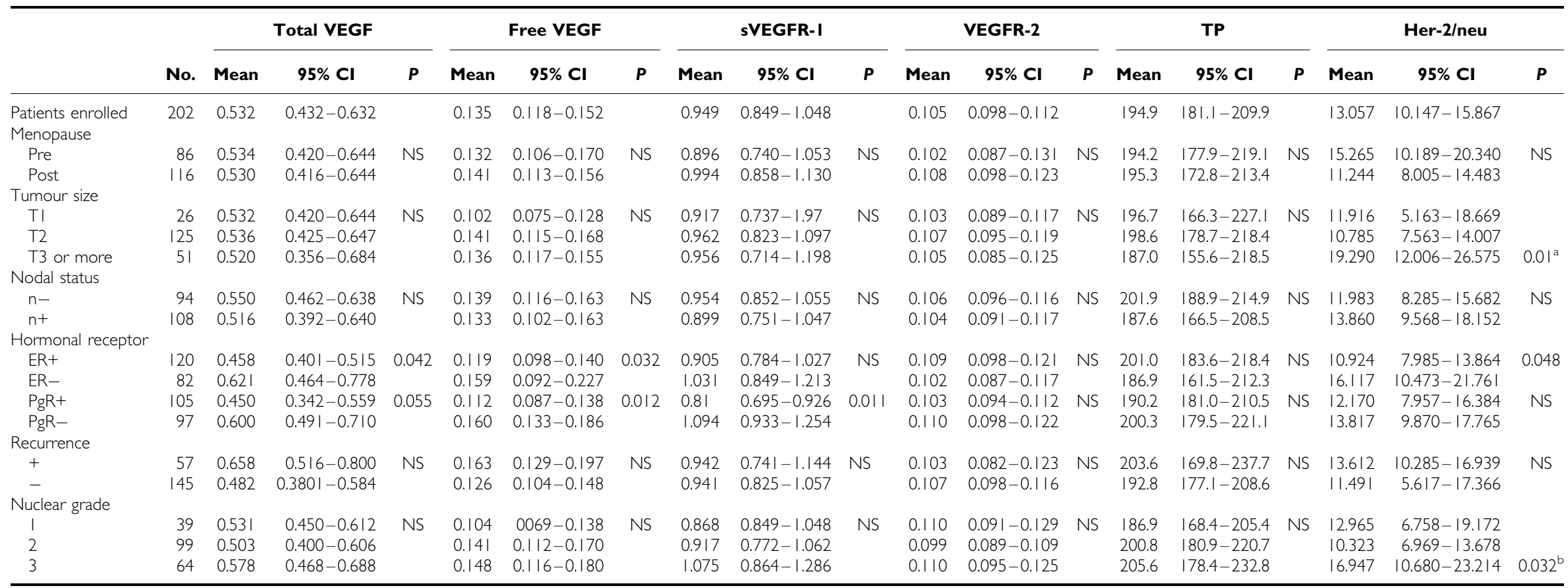

Intratumoral total and free VEGF, sVEGFR-I, VEGFR-2, TP. Her-2/neu, ER and PR protein levels were measured by quantitative ELISA and enzyme immunoassay (see 'Materials and Methods'). The results reflect the mean values, 95\%

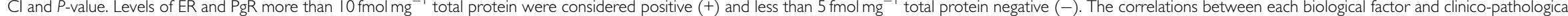

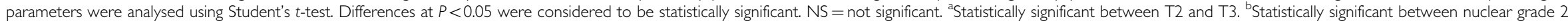
and 3 . 
Table 3 Univariate analysis of clinico-pathological and tumour biologic factors for DFS and OS

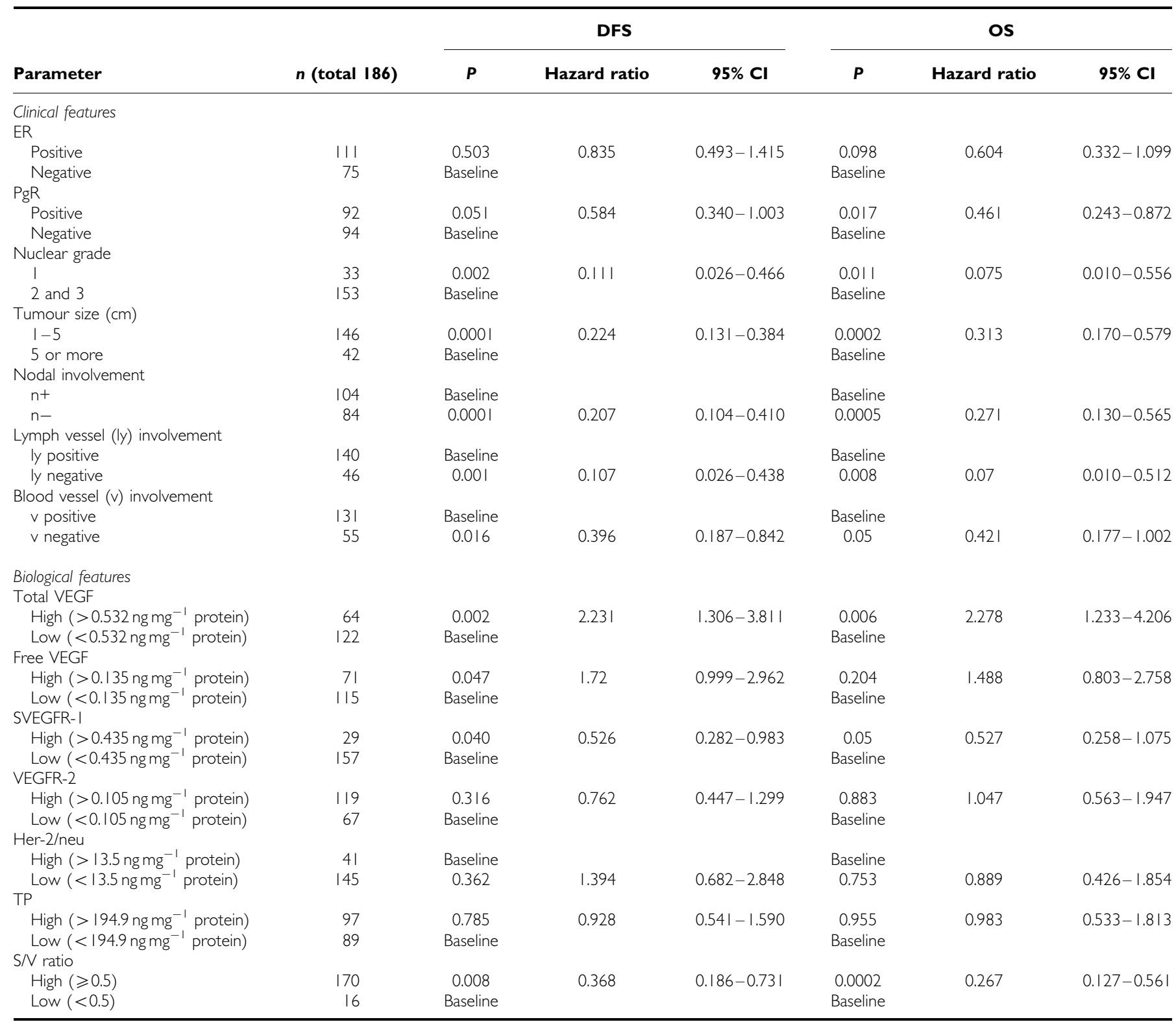

Prognostic parameters evaluated included ER and PR status $\left(<10 \mathrm{fmol} \mathrm{mg}^{-1}\right.$ protein vs more than $10 \mathrm{fmol} \mathrm{mg}^{-1}$ protein), primary tumour size, axillary lymph node involvement, total VEGF level, free VEGF level, sVEGFR-I level, VEGFR-2 level, Her-2/neu protein level, TP level and S/V ratio (sVEGFR-I/total VEGF ratio). For total and free VEGF, VEGFR-2 and Her-2 protein levels, cutoff values were determined as mean values. For sVEGFR-I and S/V ratio, cutoff values were determined according to a stepwise method (see Results). The median follow-up was 64 months. Survival analysis was performed on 186 cases excluding six patients with ductal carcinoma in situ and I0 patients who did not show up for the follow-up. The prognostic significance was assessed using the log-rank test. All $P$-values are two-sided. Hazard ratio indicated Cox model hazard ratio.

involvement $(P=0.05-0.008)$, low total VEGF level $(P=0.006)$, high sVEGFR-1 level $(P=0.05)$ and a high $\mathrm{S} / \mathrm{V}$ ratio $(P=0.0002)$. Figure 1 shows DFS curves of the tumour-related prognostic features total VEGF and sVEGFR-1. Oestrogen receptor status and VEGFR-2, Her-2/neu and TP level did not have a statistically significant effect on patient outcome in the univariate analyses.

When we assessed the prognostic value of angiogenesis-related factors in the subgroups divided by ER status, total VEGF was a significant prognostic factor for ER-positive group $(P=0.0003)$ and not for ER-negative group $(P=0.120)$ (Table 4 and Figure 1). In contrast, within the ER-negative group, sVEGFR-1 and the S/V ratio were found to be strong prognostic indicators $(P=0.001$ and 0.0001 , respectively), but this was not the case for the ER-positive group. In particular, all patients with ER-negative and low S/V ratio tumours relapsed within 4 years after surgery (Figure 1). There was also a statistically significant benefit for OS with high sVEGFR-1 or a high $\mathrm{S} / \mathrm{V}$ ratio for the ER-negative group $(P=0.03$ and 0.0002 , respectively), but not for the ER-positive group. Figure 1 shows the DFS curves for total VEGF, sVEGFR-1 and the $\mathrm{S} / \mathrm{V}$ ratio for the ER-positive population $(n=111)$ and ER-negative subpopulation $(n=75)$. The results of other subgroup analyses divided by total VEGF status, TP status and Her-2/neu status are summarised in Table 4.

All tumour- and clinico-pathological-related parameters regardless of whether they were statistically significant as seen by univariate analysis were included in the multivariate analysis. Variables showing statistically significant effects were retained and the others were dropped. The resulting multivariate analysis 
A
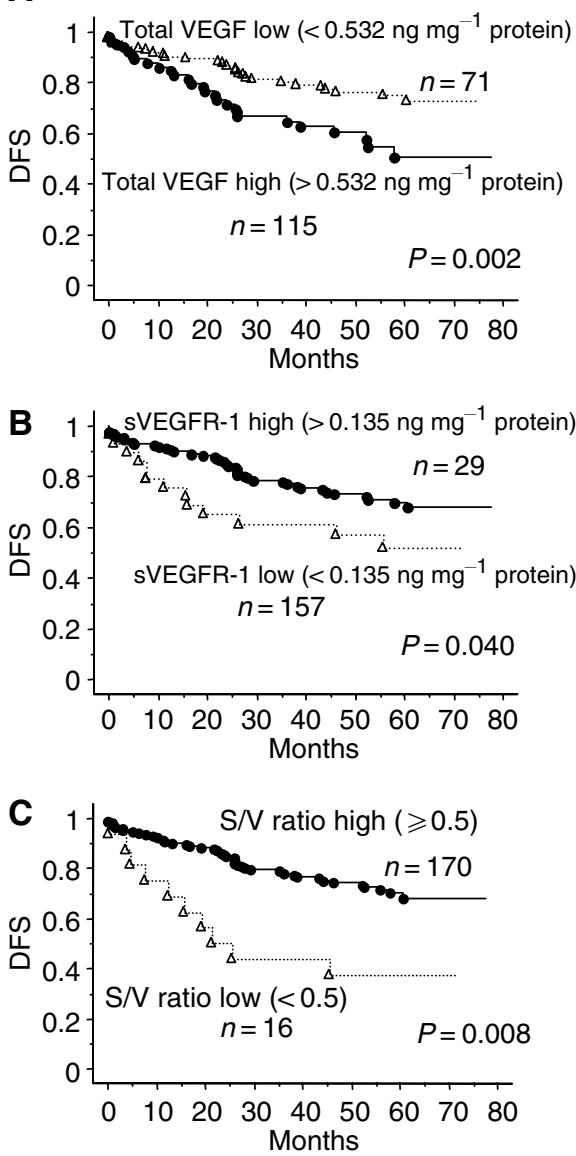

D

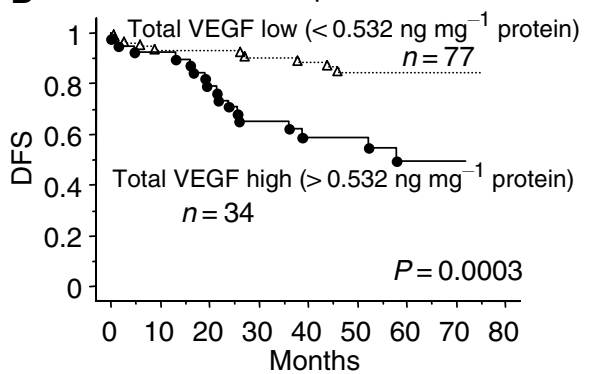

G

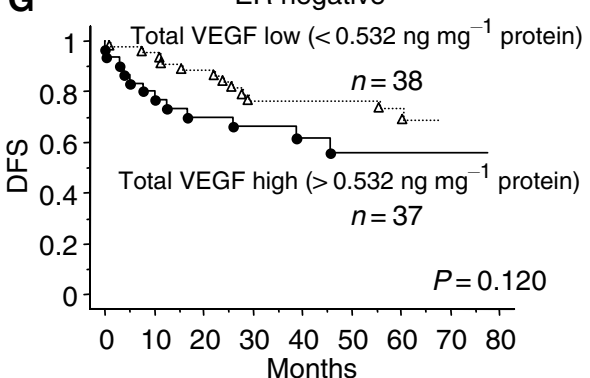

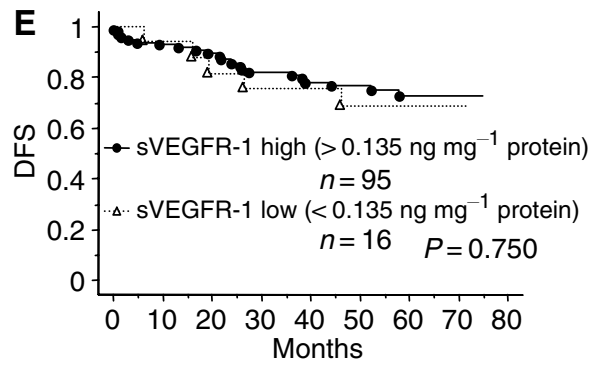
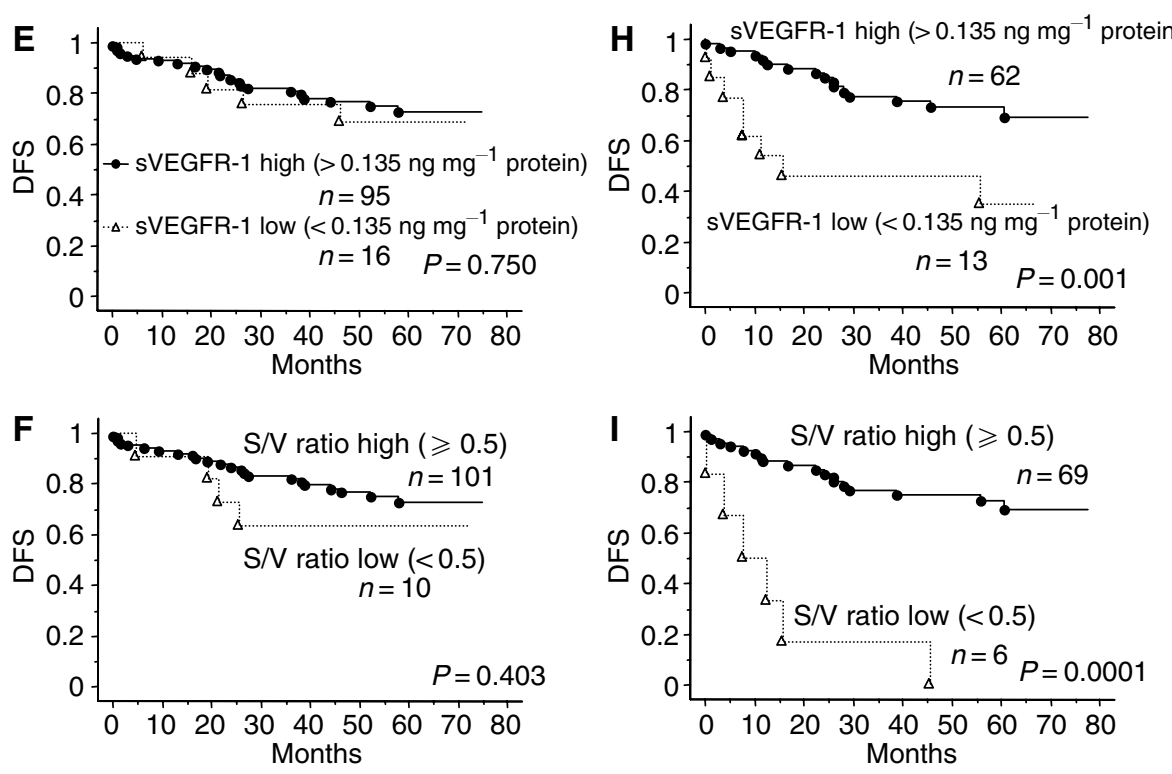

Figure I Kaplan-Meier curves for DFS in patients with primary breast cancer by biological markers. Kaplan-Meier curves for DFS in patients with primary breast cancer by biological markers. Disease free survival in the total cases $(n=186)$ by VEGF level $(\mathbf{A})$, sVEGFR-I level (B) and sVEGFR-I/ totalVEGF ratio (S/ ratio; C). Disease free survival in the ER-positive cases $(n=|| \mid$ ) by VEGF level (D), sVEGFR-I level (E) and S/V ratio (F): Disease free survival in the ER-negative cases $(n=75)$ by VEGF level $(\mathbf{G})$, sVEGFR-I level $(\mathbf{H})$ and S/V ratio (I). Levels of VEGF protein more than 0.532 ng mg ${ }^{-1}$ total protein were considered high (solid line) and less than $0.532 \mathrm{ng} \mathrm{mg}^{-1}$ total protein negative (dotted line) in (A, D and $\left.\mathbf{G}\right)$. Soluble VEGFR-I protein levels more than $0.135 \mathrm{ng} \mathrm{mg}^{-1}$ total protein were considered high (solid line) and less than $0.135 \mathrm{ng} \mathrm{mg}^{-1}$ total protein negative (dotted line) in (B, E and $\mathbf{H}$ ). S/ ratio more than 0.5 was considered high (solid line) and less than 0.5 negative (dotted line) in $(\mathbf{C}, \mathbf{F}$ and $\mathbf{I})$. $(\mathbf{A})$ The hazard ratio (HR) $=2.23(95 \%$ confidence interval $(\mathrm{Cl})=1.3 \mathrm{I}-3.8 \mathrm{I}, P=0.002$ using the log-rank test) in favour of total VEGF-low group. (B) $\mathrm{HR}=0.526(95 \% \mathrm{Cl}=0.28-0.98, P=0.04$ using the log-rank test) in favour of total sVEGFR-I-high group. (C) HR=0.368 (95\% Cl=0.19-0.73, $P=0.008$ using the log-rank test) in favour of $\mathrm{S} / \mathrm{V}$ ratio-high group. (D) In ER-positive subgroup, $\mathrm{HR}=3.800(95 \% \mathrm{Cl}=1.74-8.3 \mathrm{I}, \mathrm{P}=0.0003$ using the log-rank test) in favour of total VEGF-low group. (H) In ER-negative subgroup, $\mathrm{HR}=0.269(95 \% \mathrm{Cl}=0.1 \mathrm{I}-0.53, P=0.00$ I using the log-rank test) in favour of sVEGFR-I-high group. (I) In ER-negative subgroup, $\mathrm{HR}=0.114(95 \% \mathrm{Cl}=0.04-0.30, P=0.000$ I using the log-rank test) in favour of sVEGFR-I-high group.

revealed that DFS and OS were improved in patients with low total VEGF $(P<0.001$ and $P=0.043)$, a high $S / V$ ratio $(P=0.002$ and $0.003)$, pathological low grade $(P=0.015$ and 0.034$)$, tumour less than $5 \mathrm{~cm}$ in size $(P=0.002$ and 0.038$)$ and negative nodal involvement ( $P=0.001$ and 0.002 , respectively) (Table 5). Soluble VEGFR-1 alone did not result in improved DFS or OS.

\section{DISCUSSION}

Soluble VEGFR1 levels are frequently elevated in human breast cancer tissues. Out of 202 tumours, 155 contained higher concentrations of sVEGFR-1 than those of total VEGF. A recent study of the relationship between circulating sVEGFR-1 levels and preeclampsia reported that increased sVEGFR-1 is significantly associated with the development of preeclampsia, suggesting that immunodetectable sVEGFR-1 is biologically active (Levine et al, 2004). Regarding malignancies such as brain tumours or leukaemia, it was also documented that intratumoral or plasma sVEGFR-1 level is related to tumour phenotype or prognosis, suggesting that sVEGFR-1 plays a significant biological role not only during development or pregnancy but also in neoplasms (Lamszus et al, 2003; Hu et al, 2004).

Since simultaneous measurement of sVEGFR-1 and VEGFR-1 in the same sample is technically difficult, we were not able to compare the concentrations of sVEGFR-1 with those of VEGFR-1 directly. Nevertheless, as a preliminary study, we examined sVEGFR-1 and VEGFR-1 expressions in human umbilical vein endothelial cells (HUVECs) and in primary breast tumour tissues by Western blot using different types of lysis buffers with or without detergent. Using HUVECs as a positive control for both VEGFR-1 and sVEGFR-1, we confirmed that in the protein extract prepared without detergent, only sVEGFR-1 was detectable, and in contrast, in the protein extract prepared with detergent such as with RIPA buffer, both VEGFR-1 and sVEGFR-1 were detectable. We speculated that VEGFR-1 exists on a cell membrane, and the membrane fraction will not be lysed in a buffer without detergent. Then we examined expression of sVEGFR-1 and VEGFR-1 by Western blot analysis in 15 randomly selected primary breast cancer tissues prepared with different lysis buffers: 11 tumours had 


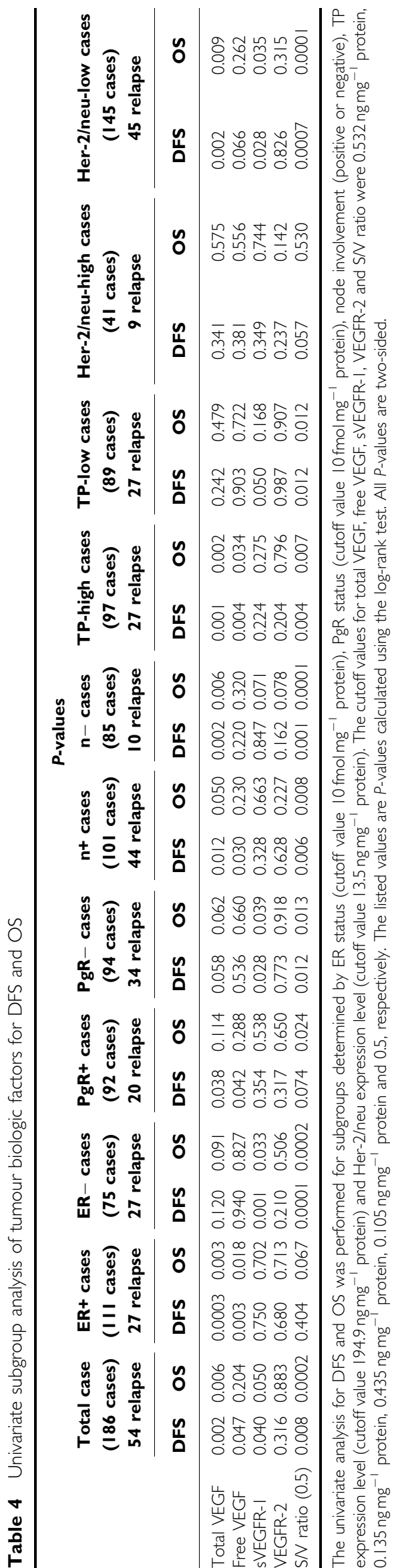

sVEGFR-1 expressions and its expressions were more dominant than VEGFR-1 expressions, and the concentration of sVEGFR-1 measured by ELISA was well correlated (data not shown). With samples treated without detergent, VEGFR-1 band was not detected in all cases. Although we have not examined all the cases that we used in the current study by Western blot analysis, the measurement of sVEGFR-1 expression with appropriate lysis buffer is meaningful with this ELISA system.

Total VEGF was determined to be a potent and independent prognostic indicator in both node-negative and node-positive cancers as reported in the previous studies (Toi et al, 2001; Ferrara et al, 2003). No significant prognostic value of free VEGF was observed in this study. It is difficult to explain why only total VEGF provides significant prognostic value but not free VEGF. Total VEGF concentration is a useful marker for predicting survival or disease progression. The current study using a highly sensitive sVEGFR-1 ELISA system confirmed that sVEGFR-1 is a significant prognostic indicator. In particular, we discovered that low sVEGFR-1 was related to an unfavourable prognosis, which was a slightly different result from that we had in a previous study with a relatively low-sensitivity sVEGFR-1 ELISA system, where we found a prognostic value of high sVEGFR-1 concentrations for favourable prognosis (Toi et al, 2002). The significance of the ratio of sVEGFR-1 to total VEGF (S/V ratio) as a prognostic marker was reconfirmed in this larger size of analysis. Particularly, a low S/V ratio was associated with unfavourable prognosis. Since sVEGFR-1 protein is estimated to be produced by both tumour cells and stromal cells in breast cancer microenvironment, it would be important to analyse the regulatory mechanisms of this balance more thoroughly.

In the subgroup analyses, we found that low sVEGFR-1 expression was significantly related to poor prognosis for ERnegative subgroup but not for ER-positive subgroup. The prognostic value of $\mathrm{S} / \mathrm{V}$ ratio also significantly associated with ER negativity, and the correlation was more relevant than sVEGFR-1 status alone. It is reported that total VEGF expression is related to a poor prognosis in ER-positive patients rather than ER-negative patients (Linderholm et al, 2000; Foekens et al, 2001; Buteau-Lozano et al, 2002; Manders et al, 2003). Therefore, it is important to consider why the prognostic value of sVEGFR-1 or S/V ratio was associated with ER-negative status. Several explanations might be possible. First, the sensitivity of endothelial cells to VEGF might be different between ER-positive tumours and ERnegative tumours. Several reports discussed that ER-positive and ER-negative tumours display remarkably different gene expression phenotypes (Gruvberger et al, 2001). Also, ER-negative tumour cells produced larger amounts of growth factors and cytokines that can stimulate various types of cells including endothelial cells (Bando et al, 2003). Second, adjuvant therapies, especially postoperative hormone therapy, might cause a difference in the survival analysis between ER-positive and ER-negative subgroups. It is known that hormone treatments such as tamoxifen can downregulate VEGF expression in hormone-sensitive breast tumour cells or tumour tissues (Garvin and Dabrosin, 2003). In addition, it was recently documented that sVEGFR-1 was inducible in normal breast cell line and human breast cancer cell line, MCF7, with hormone-dependent property in response to anti-oestrogen treatments (Elkin et al, 2004). In those cells, oestrogen was a potent downregulator of sVEGFR-1, and ER antagonism blocked the action dramatically. In the present study using nontreated primary tumours, sVEGFR-1 levels were significantly higher in PgRnegative tumours rather than PgR-positive tumours, which seems to support the idea that sVEGFR-1 is downregulated in purely hormone-dependent tumours such as ER-positive and PgRpositive tumours. According to these data, it might be possible to hypothesise that adjuvant hormonal treatments may suppress disease progression in patients having low $\mathrm{S} / \mathrm{V}$ ratio, which is basically associated with poor survival, by modulating those 
Table 5 Multivariate analysis of clinico-pathological and tumour biologic factors for DFS and OS

\begin{tabular}{|c|c|c|c|c|c|c|}
\hline \multirow[b]{2}{*}{ Parameter } & \multicolumn{3}{|c|}{ DFS } & \multicolumn{3}{|c|}{ OS } \\
\hline & Hazard ratio & $95 \% \mathrm{Cl}$ & $P$ & Hazard ratio & $95 \% \mathrm{Cl}$ & $\boldsymbol{P}$ \\
\hline Nuclear grade | & 0.172 & $0.041-0.598$ & 0.015 & 0.132 & $0.016-0.861$ & 0.034 \\
\hline Tumour size $<5 \mathrm{~cm}$ & 0.391 & $0.215-0.713$ & 0.002 & 0.502 & $0.261-0.965$ & 0.038 \\
\hline Node negative & 0.269 & $0.121-0.598$ & 0.001 & 0.3 & $0.136-0.656$ & 0.002 \\
\hline VEGF-A (<0.532 $\mathrm{ng} \mathrm{mg}^{-1}$ protein) & 0.458 & $0.257-0.814$ & $<0.001$ & 0.499 & $0.256-0.972$ & 0.043 \\
\hline sVEGFR-I/total VEGF-A >0.5 & 0.225 & $0.107-0.472$ & 0.002 & 0.295 & $0.131-0.666$ & 0.003 \\
\hline
\end{tabular}

Hazard ratio indicates Cox model proportional hazard ratio; $P$ is the Wald model $P$-value.

expressions. In ER-negative patients, theoretically it does not happen. Many other possibilities could be raised to explain this translational research question.

Another important finding observed in subgroup analyses is that the total VEGF and sVEGFR-1 levels as well as the S/V ratio exhibited significant prognostic importance for low Her-2/neu tumours but not for high Her-2/neu tumours (Table 4). Transfection of the Her-2/neu gene enhances VEGF expression in breast cancer experimental models (Yen et al, 2000). In this study, the intratumoral concentrations of Her-2/neu were significantly correlated with those of VEGF. The regulatory mechanism of VEGF and sVEGFR-1 expressions could be different between Her-2/neu-positive and Her-2/neu-negative subgroups.

As to the regulatory mechanism of sVEGFR-1, several factors such as growth mediators and hypoxia are reported to induce the expression of VEGFR-1 and sVEGFR-1 in endothelial cells (Barleon et al, 1997). Among these inducers, hypoxia might be a key factor especially, because it is capable of regulating the expressions of multiple angiogenesis-related molecules simultaneously (Griffiths et al, 1997; Bando et al, 2003). It was found in this study that the intratumoral concentration of sVEGFR-1 significantly correlated with those of VEGFR-2, total VEGF, free VEGF and TP. Therefore, it is interesting to know the relationship with the markers of hypoxia in future analysis, and to understand the machinery of alternative splicing of sVEGFR-1 in both tumourassociated stromal cells and hormone-dependent cancer cells.

\section{REFERENCES}

Bando H, Toi M, Kitada K, Koike M (2003) Genes commonly upregulated by hypoxia in human breast cancer cells MCF-7 and MDA-MB-231. Biomed Pharmacother 57: 333-340

Barleon B, Siemeister G, Martiny-Baron G, Weindel K, Herzog C, Marme D (1997) Vascular endothelial growth factor up-regulates its receptor fmslike tyrosine kinase 1 (FLT-1) and a soluble variant of FLT-1 in human vascular endothelial cells. Cancer Res 57: $5421-5425$

Buteau-Lozano H, Ancelin M, Lardeux B, Milanini J, Perrot-Applanat M (2002) Transcriptional regulation of vascular endothelial growth factor by estradiol and tamoxifen in breast cancer cells: a complex interplay between estrogen receptors alpha and beta. Cancer Res 62: 4977-4984

Elkin M, Orgel A, Kleinman HK (2004) An angiogenic switch in breast cancer involves estrogen and soluble vascular endothelial growth factor receptor 1. J Natl Cancer Inst 96: 875-878

Ferrara N, Alitalo K (1999) Clinical applications of angiogenic growth factors and their inhibitors. Nat Med 5: 1359-1364

Ferrara N, Gerber HP, LeCouter J (2003) The biology of VEGF and its receptors. Nat Med 9: 669-676

Foekens JA, Peters HA, Grebenchtchikov N, Look MP, Meijer-van Gelder ME, Geurts-Moespot A, van der Kwast TH, Sweep CG, Klijn JG (2001) High tumor levels of vascular endothelial growth factor predict poor response to systemic therapy in advanced breast cancer. Cancer Res 61: $5407-5414$
In conclusion, the intratumoral concentration of sVEGFR-1 and VEGF and the ratio of sVEGFR-1 to total VEGF were potent prognostic indicators in 202 primary breast tumours in our study. The expression level and the balance between VEGF and sVEGFR-1 molecules were thought to be important to understand the hormone dependency of breast cancer and the sensitivity or resistance to hormonal therapy. Recently, it was clinically demonstrated that anti-VEGF therapy brings survival benefit to cancer patients in colorectal cancer patients (Hurwitz et al, 2004). We speculate that the determination of VEGF and sVEGFR-1 will also be useful to distinguish anti-VEGF therapy-sensitive tumours from less sensitive tumours. Eventually, the quantification of VEGF and its related molecules will be important for understanding the tumour growth machinery, the disease progression and the survival prediction of primary breast cancer and for considering treatment strategies with hormonal therapies and antiangiogenesis therapies.

\section{ACKNOWLEDGEMENTS}

This study was sponsored by International Union Against Cancer (UICC), Translational Cancer Research Fellowships (TCRF), Deutsche Forschungsgemeinschaft (grant number SPP1069) and Tokyo Metropolitan Special Research Grant.
Garvin S, Dabrosin C (2003) Tamoxifen inhibits secretion of vascular endothelial growth factor in breast cancer in vivo. Cancer Res 63: 8742 8748

Gasparini G (2000) Prognostic value of vascular endothelial growth factor in breast cancer. Oncologist 5: 37-44

Goldman CK, Kendall RL, Cabrera G, Soroceanu L, Heike Y, Gillespie GY, Siegal GP, Mao X, Bett AJ, Huckle WR, Thomas KA, Curiel DT (1998) Paracrine expression of a native soluble vascular endothelial growth factor receptor inhibits tumor growth, metastasis, and mortality rate. Proc Natl Acad Sci USA 95: 8795-8800

Griffiths L, Dachs GU, Bicknell R, Harris AL, Stratford IJ (1997) The influence of oxygen tension and $\mathrm{pH}$ on the expression of plateletderived endothelial cell growth factor/thymidine phosphorylase in human breast tumor cells grown in vitro and in vivo. Cancer Res 5: $570-572$

Gruvberger S, Ringner M, Chen Y, Panavally S, Saal LH, Borg A, Ferno M, Peterson C, Meltzer PS (2001) Estrogen receptor status in breast cancer is associated with remarkably distinct gene expression patterns. Cancer Res 61: $5979-5984$

Hornig C, Behn T, Bartsch W, Yayon A, Weich HA (1999) Detection and quantification of complexed and free soluble human vascular endothelial growth factor receptor-1 (sVEGFR-1) by ELISA. J Immunol Methods 226 $169-177$ 
Hoshida T, Sunamura M, Duda DG, Egawa S, Miyazaki S, Shineha R, Hamada H, Ohtani H, Satomi S, Matsuno S (2002) Gene therapy for pancreatic cancer using an adenovirus vector encoding soluble flt-1 vascular endothelial growth factor receptor. Pancreas 25: 111-121

Hu Q, Dey AL, Yang Y, Shen Y, Jilani IB, Estey EH, Kantarjian HM, Giles FJ, Albitar M (2004) Soluble vascular endothelial growth factor receptor 1, and not receptor 2, is an independent prognostic factor in acute myeloid leukemia and myelodysplastic syndromes. Cancer 100: 1884-1891

Hurwitz H, Fehrenbacher L, Novotny W, Cartwright T, Hainsworth J, Heim W, Berlin J, Baron A, Griffing S, Holmgren E, Ferrara N, Fyfe G, Rogers B, Ross R, Kabbinavar F (2004) Bevacizumab plus irinotecan, fluorouracil, and leucovorin for metastatic colorectal cancer. $N$ Engl J Med 350: 2335-2342

Kendall RL, Thomas KA (1993) Inhibition of vascular endothelial cell growth factor activity by an endogenously encoded soluble receptor. Proc Natl Acad Sci USA 90: 10705-10709

Kendall RL, Wang G, Thomas KA (1996) Identification of a natural soluble form of the vascular endothelial growth factor receptor, FLT-1, and its heterodimerization with KDR. Biochem Biophys Res Commun 226: 324-328

Lamszus K, Ulbricht U, Matschke J, Brockmann MA, Fillbrandt R, Westphal M (2003) Levels of soluble vascular endothelial growth factor (VEGF) receptor 1 in astrocytic tumors and its relation to malignancy, vascularity, and VEGF-A. Clin Cancer Res 9: 1399-1405

Levine RJ, Maynard SE, Qian C, Lim KH, England LJ, Yu KF, Schisterman EF, Thadhani R, Sachs BP, Epstein FH, Sibai BM, Sukhatme VP, Karumanchi SA (2004) Circulating angiogenic factors and the risk of preeclampsia. $N$ Engl J Med 350: 672-683

Linderholm B, Grankvist K, Wilking N, Johansson M, Tavelin B, Henriksson R (2000) Correlation of vascular endothelial growth factor content with recurrences, survival, and first relapse site in primary node- positive breast carcinoma after adjuvant treatment. J Clin Oncol 18: $1423-1431$

Mahasreshti PJ, Navarro JG, Kataram M, Wang MH, Carey D, Siegal GP, Barnes MN, Nettelbeck DM, Alvarez RD, Hemminki A, Curiel DT (2001) Adenovirus-mediated soluble FLT-1 gene therapy for ovarian carcinoma. Clin Cancer Res 7: 2057-2066

Manders P, Beex LV, Tjan-Heijnen VC, Span PN, Sweep CG (2003) Vascular endothelial growth factor is associated with the efficacy of endocrine therapy in patients with advanced breast carcinoma. Cancer 98: 21252132

Sako A, Kitayama J, Koyama H, Ueno H, Uchida H, Hamada H, Nagawa H (2004) Transduction of soluble Flt-1 gene to peritoneal mesothelial cells can effectively suppress peritoneal metastasis of gastric cancer. Cancer Res 64: 3624-3628

Shibuya M (2001) Structure and function of VEGF/VEGF-receptor system involved in angiogenesis. Cell Struct Funct 26: 25-35

Takayama K, Ueno H, Nakanishi Y, Sakamoto T, Inoue K, Shimizu K, Oohashi H, Hara N (2000) Suppression of tumor angiogenesis and growth by gene transfer of a soluble form of vascular endothelial growth factor receptor into a remote organ. Cancer Res 60: 2169-2177

Toi M, Bando H, Ogawa T, Muta M, Hornig C, Weich HA (2002) Significance of vascular endothelial growth factor (VEGF)/soluble VEGF receptor-1 relationship in breast cancer. Int J Cancer 98: 14-18

Toi M, Matsumoto T, Bando H (2001) Vascular endothelial growth factor: its prognostic, predictive, and therapeutic implications. Lancet Oncol 2: $667-673$

Yen L, You XL, Al Moustafa AE, Batist G, Hynes NE, Mader S, Meloche S, Alaoui-Jamali MA (2000) Heregulin selectively upregulates vascular endothelial growth factor secretion in cancer cells and stimulates angiogenesis. Oncogene 19: 3460 - 3469 